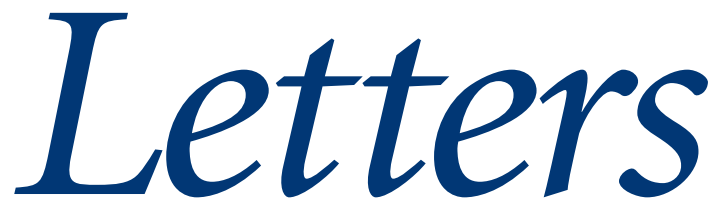

All letters are subject to editing and may be shortened. Letters should be sent to the BJGP office by e-mail in the first instance, addressed to

journal@rcgp.org.uk (please include your postal address). Alternatively, they may be sent by post as an MS Word or plain text version on CD or DVD. We regret that we cannot notify authors regarding publication. Letters not published in the Journal may be posted online on our Discussion Forum. For instructions please visit: http://www.rcgp.org.uk/bjgp-discuss

\section{Real life ethics}

We were very interested to read the case report in the April' issue of the journal. It highlights the importance of patient autonomy and of allowing patients to make their own decisions regarding future care. What is concerning in the case described is that the patient's specific wishes were not followed. The patient had explicitly stated she did not wish to be hospitalised and wanted nature to take its course. However, when the patient was very unwell and became unconscious, the decision was made by the GP to hospitalise the patient (albeit not the hospital she had stated that she did not wish to be admitted to) 25 miles away from her home.

Surely, the patient could have been managed differently - was it not possible to obtain rectal diazepam from a pharmacy? Also would it not have been possible to liaise with the local palliative care and district nursing teams to arrange for a syringe driver to be set up at home to allow the patient to be managed in her place of choice? Palliative care is about forward planning and decision making. Spending a night in A\&E, followed by a week on a general ward does not usually afford good palliative care and in this case the response of the GP made a mockery of this patient's desire to have some control over the last days of her life.

\section{Mari Lloyd-Williams}

Professor/Director of Academic Palliative and Supportive Care Studies Group, Division of Primary Care, University of Liverpool, L69 3GB.

E-mail: m/w@liverpool.ac.uk

\section{Joanne Reeve}

Walport Lecturer, Department of Primary Care, University of Manchester.

\section{REFERENCE}

1. Brown E, Pink J. Real life ethics: autonomy versus duty of care. Br J Gen Pract 2008; 58(549): 288-289.

DOI: 10.3399/bjgp08X319495

\section{Author's response}

Professor Lloyd-Williams and Dr Reeve clearly share our commitment to respecting patient autonomy in health care. It is because of this commitment that we highlighted practical barriers that can arise during emergency care within a complex multi-agency system governed by a variety of rules and procedures that are often not compatible. We can probably all agree too that services should be developed in a way that takes account of such problems.

\section{Eleanor Brown}

Cardiff Road Surgery, Mountain Ash, South Wales.

E-mail: Eleanor.Brown@gpw95623.wales.nhs.uk

DOI: 10.3399/bjgp08X319503

\section{Preoperative anaemia}

Blood transfusion may be beneficial and life saving in particular clinical situations. However, transfusions do carry some risks. Blood is a limited resource and liable to shortage at times of peak demand. Total hip replacement surgery accounts for $4.6 \%$ of blood used in hospitals and studies have shown a wide variation in transfusion practice for this procedure. A pre-operative haemoglobin $(\mathrm{Hb})$ of less than $12 \mathrm{~g} / \mathrm{dl}$ increases the likelihood of transfusion threefold.

NHS Blood and Transplant, in collaboration with the Royal College of Physicians, carry out a series of 'national comparative audits' on transfusion practice, acknowledged by the Healthcare Commission. These audits evaluate safety of transfusion and appropriateness of blood usage. The aim of this prospective audit was to measure transfusion practice in 'primary total hip replacement' surgery (THR) against two performance indicators and four practice standards. The audit report highlighted deficiencies in practice nationally and made recommendations to improve transfusion practice.

Two hundred and twenty-three hospitals submitted data for 7465 patients who underwent THR. Nationally, $25 \%$ of patients were transfused and the transfusion rate among hospitals varied from 0 to $100 \%$. The audit found that, nationally, $29 \%$ of patients did not have a $\mathrm{Hb}$ estimation pre-operatively, and $15 \%$ went for surgery with a $\mathrm{Hb}$ less than $12 \mathrm{~g} / \mathrm{dl}$. To minimise the likelihood of patients receiving blood transfusions, preoperative anaemia should be corrected as far as possible. Hospitals should have a written policy for identification and management of anaemia in pre-assessment clinics. Surgeons seeing patients at initial consultation must ensure that patients have a full blood count, and that patients with anaemia are investigated and steps are taken to correct the anaemia before surgery. GPs referring patients for surgery should take measures to optimise the haemoglobin.

Studies have shown that previously undiagnosed anaemia is identified in more than $30 \%$ of patients undergoing elective surgery and a third of these are due to iron deficiency. This anaemia in the absence of chronic blood loss responds well to oral iron. It takes several weeks to optimise the haemoglobin and there may not be 
sufficient time to correct the anaemia in the pre-assessment before surgery. Therefore, we propose that at the point when a GP decides that a patient is likely to need arthroplasty, tests are done to identify anaemia and where necessary treat with haematinics before the initial orthopaedic consultation.

\section{Hari Boralessa}

Consultant Transfusion Medicine, National Blood Service, Crescent Drive, Brentwood, Essex, CM15 8DP.

E-mail: hari.boralessa@nhsbt.nhs.uk

DOI: 10.3399/bjgp08X319512

\section{Death certification post Shipman}

A decade after Shipman's arrest ${ }^{1}$ and 4 years since the Shipman Inquiry report into death certification was published, ${ }^{2}$ the key proposals have been scarcely debated, let alone any having led to serious action. We believe this failure may be due to the tenor of the inquiry's proposals which saw death as a potentially criminal act to be forensically investigated, rather than an opportunity for proper certification and potential learning. ${ }^{3}$

The present impasse leaves us worse off than a decade ago, as no one can be satisfied with the current system which is known to be seriously flawed, yet there is clear doubt as to how to proceed. Indeed, locally introduced variations of certification practice, especially regarding cremation, probably abound.

We consider that the Royal College of General Practitioners is best placed to reopen the debate publicly about death certification. The suggestion of 'pilot schemes during 2008'3 should be actively pursued and College members and others encouraged to participate.

Each death is a significant event and many have lessons for future practice. In our experience these are essential learning opportunities that ought to be part of each doctor's revalidation portfolio. ${ }^{3}$ For those doctors and teams who are struggling to perform adequately, it is also our experience that a search through the records of the patients who have died can reveal both clinical and systems problems far more quickly than anything else.

'A retrospective search for avoidable factors in individual deaths is perhaps the most stringent form of self-criticism available to any clinical team.' ${ }^{4}$

\section{John Holden}

Garswood Surgery, Garswood, St Helens, WN4 OXD. E-mail: john@holdens.org.uk

\section{Steve Cox}

The Spinney Medical Centre, Whittle Street, St Helens, Merseyside, WA10 3EB.

\section{REFERENCES}

1. Baker R. Making haste slowly: the response to the Shipman Inquiry? Br J Gen Pract 2008; 58(550): 307-308.

2. The Shipman Inquiry. Fifth Report. Safeguarding patients : lessons from the past - proposals for the future. The Shipman Inquiry, 2004. http://www theshipman-inquiry.org.uk/fifthreport.asp (accessed 12 Jun 2008).

3. Holden J, O'Donnell S, Brindley J, Miles L. Analysis of 1263 deaths in four general practices. Br J Gen Pract 1998; 48(432): 1409-1412.

4. Hart JT, Humphreys C. Be your own coroner: an audit of 500 consecutive deaths in general practice. BMJ 1987; 294(6576): 871-874.

DOI: 10.3399/bjgp08X319521

\section{'Home Office syndrome'}

We wish to offer a name for a syndrome which will be familiar to those working with refugees and asylum seekers. While asylum seekers are awaiting a Home Office decision on their asylum claim, they often give no attention to their other needs; in particular, their health needs. This is because they often fear that they will be killed or tortured if they are returned to the countries from which they came.

The health and health behaviours of asylum seekers are strongly influenced by their social circumstances - starting with the events that have happened in the countries they have come from, the stress of separation from their family and everything that is familiar, and the difficulties they face here. Once in the UK, taking care of their health, or bothering to take tablets for conditions, such as high blood pressure or diabetes, seems unimportant compared to the immediate problems of survival. Health problems take second place to the progress of their asylum case - people will miss important appointments with their GP or hospital specialist to see their solicitor.

The 'Home Office syndrome' is perhaps a specific example of Maslow's hierarchy of needs. While the individual is dealing with what he perceives to be a threat to his life, all other matters, including health care, are put on hold.

The delays in deciding asylum status have been long and may still last months. As a result, the 'Home Office syndrome' is bad for the health of asylum seekers who may wait long periods before they seek appropriate help for their health needs. Other examples of policies that damage the health of asylum seekers are those that prevent legal employment, ${ }^{1}$ and the refusal of secondary health care for 'failed' asylum seekers. The last policy has recently been judged illegal in the High Court. ${ }^{2}$

\section{Gervase Vernon}

GP and medico-legal report writer, Medical Foundation for the Care of Victims of Torture, London, N7 7JW.

\section{Dave Ridley}

Practice Nurse, Cape Hill Medical Centre, Smethwick, West Midlands.

\section{Dineo Lesetedi}

Practice Nurse, The Meridian Practice, Coventry.

\section{REFERENCES}

1. Vernon G, Feldman R. Refugees in primary care: from looking after to working together.

http://www.networks.nhs.uk/uploads/06/06/refugees in_primary_care.doc (accessed 12 Jul 2008).

2. Department of Health. Failed asylum seekers and ordinary residence.

http://www.dh.gov.uk/en/Publicationsandstatistics/Le ttersandcirculars/Dearcolleagueletters/DH_084479. (accessed 12 Jul 2008)

DOI: 10.3399/bjgp08X319530 